Dargham AS., Assaf S., Faour K., Hamzeh, F. (2019). "Optimizing Material-Related Costs Using Dynamic Site Layout and Supply Chain Planning." In: Proc. $27^{\text {th }}$ Annual Conference of the International. Group for Lean Construction (IGLC), Pasquire C. and Hamzeh F.R. (ed.), Dublin, Ireland, pp. 699-710. DOI: https://doi.org/10.24928/2019/0135. Available at: 〈www.iglc.net>.

\title{
OPTIMIZING MATERIAL-RELATED COSTS USING DYNAMIC SITE LAYOUT AND SUPPLY CHAIN PLANNING
}

\author{
Sarah Abou Dargham ${ }^{1}$, Sena Assaf ${ }^{2}$, Karim Faour ${ }^{3}$, and Farook Hamzeh ${ }^{4}$
}

\begin{abstract}
Understanding a construction site layout is a crucial step before allocating resources to it; space is a critical factor that impacts both labor productivity and ease of material reach when needed. There is little research performed on the cost aspect of material management on site in compliance with the schedule and the type of supply chain strategy. The process of delivering bulk Glass Reinforced Concrete (GRC) units based on a push-supply system to a congested site with limited storage space all the way to their storage and installation on site is studied in this paper. The resources' cost, deterioration cost, transportation-delay cost, and the corresponding space turnover rate associated with the process are also addressed. The aim of this paper is to incorporate lean thinking to develop, model, and simulate an optimized and dynamic site layout that allows for a smooth flow of materials to the site thus minimizing their accumulated logistics and handling costs using the simulation software EZStrobe. Results showed $16 \%$ reduction in the total cost and $15 \%$ in the total simulation time from the base model of the process under study by adopting a pull-based supply chain of GRC units and combining certain activities of the process.
\end{abstract}

\section{KEYWORDS}

Dynamic site layout planning, lean construction, supply chain management, material handling cost, workflow.

\section{INTRODUCTION}

Planning how a site reacts to the materials it receives every day is a critical part of planning and scheduling. Materials should arrive to the site when they are needed, at the quality level desired, and in the quantities desired. This then helps to reduce the non-value adding activities, thus reducing the accompanied costs and consequently adding value to the

1 Graduate Student, Civil and Environmental Engineering Department, American University of Beirut, Lebanon, Phone +961 76547 177, sra26@ mail.aub.edu

2 Graduate Student, Civil and Environmental Engineering Department, American University of Beirut, Lebanon, Phone+961 71834 900, saa127@ mail.aub.edu

3 Civil Engineering Graduate, Civil and Environmental Engineering Department, American University of Beirut, Lebanon, Phone +961 71112 886, knf03@ mail.aub.edu

4 Associate Professor, Civil and Environmental Engineering Department, University of Alberta, Canada, hamzeh@ualberta.ca 
process (Lange \& Schilling, 2015). Moreover, it is important to continuously assess how a site reacts to the multiple material inflows and outflows within it in order to better understand how to efficiently integrate the overall supply chain with the project schedule.

Space on site is usually used to accommodate temporary facilities, material storage areas, as well as the ongoing construction works (Said \& El-Rayes, 2013). However, space availability is often considered limited in several construction projects. Projects with congested sites require an even more detailed planning of logistics (Mossman, 2007) and must be addressed early on in the planning phase to help in decisions regarding off-site laydown areas and off-site construction (Tommelein and Zouein, 1993). As a result, construction managers aim at developing site layout plans that utilize the space use on site. In fact, this utilization is optimum when it considers the dynamic change of the construction project, and if it takes into account the critical activities of the project's schedule.

Site layout planning in construction sites could be classified into static or dynamic layouts. The "static site layout planning" simplifies the site layout model since it does not allow materials and facilities to change their location over the project duration. On the other hand, "dynamic site layout planning" incorporates the complexity of material procurement, storage, and handling based on site and schedule needs (Said \& El-Rayes, 2013). Alternative layout designs are often evaluated based on the material handling cost. As a result, facilities in a production system are to be located based on minimal material handling cost which accounts for material flow quantity and the distance separating the facilities (Turanoglu \& Akkaya, 2017).

In order to tackle the problem of managing materials within a congested site, Said and El-Rayes (2013) proposed computational algorithms to model interior space allocation and the impact of space utilization on activity scheduling. The resulting model provides optimal logistics layout plans based on the least logistics cost and project schedule.

Moreover, the lean construction community has addressed the concepts of space allocation on site and site layout planning. A space scheduling program known as LOSite was developed by Bascoul and Tommelein (2017) based on visual management techniques. Its aim was to visualize the completed works per trade in the interiors phase of a project. The program was proven to be beneficial for subcontractors working on large scale projects since it simplifies planning for manpower. It has also helped the general contractor to spot errors in the schedule and to avoid space overlap between concurrent activities thus coordinating the work flow. Superintendents were also able to follow up on the commitments of resources from subcontractors. Moreover, MovePlan -a graphical and interactive program- was developed by Tommelein and Zouein (1993) for the purpose of developing dynamic site layouts over discrete time intervals. It allows the user to move and position resources on site to develop and assess several site layout alternatives.

The theory of production revolves around three key areas: transformation, flow, and value generation (TFV) (Bertelsen and Koskela, 2002). Koskela (2000) identified seven groups of resource flows that are necessary to complete a certain task. Those include: construction design, components and materials, workers, equipment, space, connecting works, in addition to external conditions. Moreover, various types of flow have been identified that tackle the issue of flow from various perspectives. One type of flow is called 
"even flow" that includes leveling resources with the goal of enhancing production rates and making the production process smoother (Kraemer et al., 2007).

Tiwari et al. (2018) addressed the issue of the lack of proper communication between a fabrication shop and the construction site that could result in material waste, material overproduction, and logistic-related problems leading to overall delays. For those reasons, they developed a software application that ensures smooth information flow and lean material flow from the fabrication shop to the site.

A huge portion of construction costs is attributed to the construction materials and equipment being used. In fact, these comprise 60 to 70 percent of the total direct project cost, with the remaining 30 to 40 percent being allocated for labor costs (Patel \& Vyas, 2011). Total project costs accumulate whenever material is being moved from one place to another on and off site. Material movement includes bringing material into the site from surrounding laydown areas and storage facilities or transporting material that are onsite/off-site to their respective assembly or installation areas (Tommelein, 1994). Another main sources of waste in construction sites is directly related to the push nature of activities. Push systems are based on scheduled dates for releasing work into the following process disregarding the system's current state (Alves, Tommelein, \& Ballard, 2006).

Optimizing any construction process requires a lean approach to obtain enhanced results. Given that simulation tools allow better decision-making capabilities, integrating lean methods enables better system configurations with the inputs available (Uriarte, Moris, \& Oscarsson, 2015). On the other hand, production systems can employ simulation techniques to address and resolve many of the inherent deficiencies as stated by Standridge and Marvel (2006). Hamzeh et al. (2007) employed simulation to show the reduced amount of inventory needed in a system when integrating logistics centers into a contractor's supply chain. As a matter of fact, Tommelein (1997) showed the importance of the information that can be generated by using Discrete Event Simulation (DES) through studying construction processes of both discrete and bulk materials. Such information could be used to better design those processes in a leaner way. This was done by analyzing the simulation models based on lean construction concepts that were incorporated within the models: waste, push versus pull, uncertainty, conversion and flow.

Stroboscope is a discrete event simulation software used to model complex processes (Martinez,1996). This software was used by several practitioners to model construction operations since it can provide the resources' states and properties and take relevant actions (Alves, Tommelein, \& Ballard, 2006). EZStrobe is a simplified version of stroboscope characterized by simple programming and real-time simulation results (Martinez, 1996).

As previously shown, methods and models in the literature that have tackled material handling on site have accounted for on-site congestion, logistics cost, project schedule, material flow to the site, in addition to dynamic site layout planning. However, the impact of how all those individual factors act and interact with one another in a single production system to incur material moving costs is understudied. Therefore, the aim of this paper is to incorporate lean thinking into developing a simulation model that determines an optimized dynamic site system with regards to minimizing material-related costs. 


\section{METHODOLOGY}

This paper summarizes an empirical research addressing dynamic site layout planning to minimize costs associated with material transportation while following a project schedule. The research involves conducting a case study. First, the construction site was identified based on space limitation and material overflow. Then, information was gathered through three in-depth interviews with construction managers and foremen regarding space usage allocation on site, description of the bulk Glass Reinforced Concrete (GRC) units used in the facade, their quantities, their procurement process, their installation process and schedule, the time associated with each activity of the processes, the supply chain stakeholders, in addition to the unit costs of the resources used in this process. These inputs were used to identify limitations of the current strategies and possible cost-related inefficiencies associated with material transport around site.

After that, site-related variables were identified such as site area, number of temporary facilities, laydown areas, number of crews available for work, and types of equipment present on site as well as their usage costs. Then a schedule for the project phase under study is prepared and critical activities were identified. Afterwards, space availability was mapped according to critical activities with material handling costs (related to labor, equipment, and storage) being recorded at every allocation and re-allocation of material around site. This information was then used to model the construction process under study on EZStrobe. The developed simulation model aims to minimize costs associated with material delivery and transport around the site for the first eight weeks of the project under study taking into account the overlap between the activities.

\section{DEFINING THE PROJECT}

Based on the interviews, the construction project under study is a static, congested site with a limited storage space leading to challenges regarding material handling of bulk GRC units as part of the façade. These units are of various shapes and each has an average area of $13 \mathrm{~m}^{2}$ with custom made racks for storage on site where each can fit ten pieces of GRC. They are manufactured off-site then transported to the site where they are placed on specified racks. After that, they undergo a series of operations such as cleaning and intersite transportation to reach their desired installation area, which is one of the eight installation zones. Figure 1 below illustrates the zone distribution for the project. Figure 2 shows a rack holding GRC units.

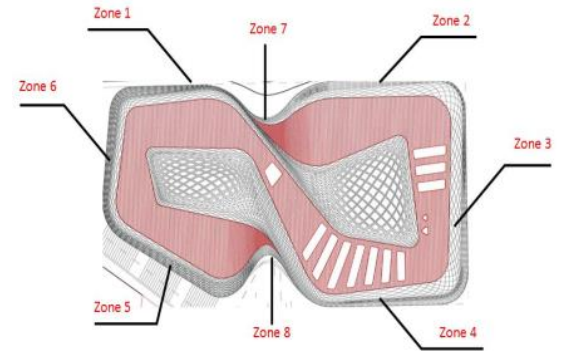

Figure 1: GRC Installation Zones

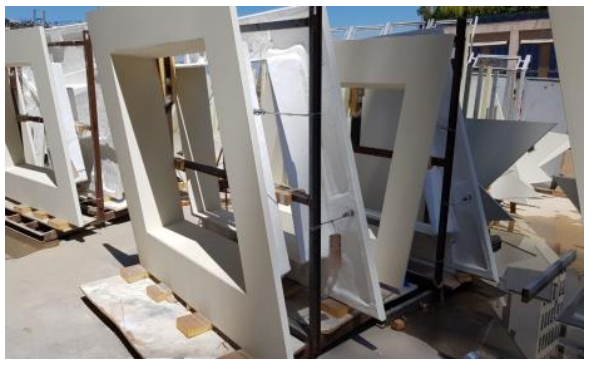

Figure 2: GRC Units Held on Rack 
Table 1 shows the quantities of GRC units needed to be installed per zone.

Table 1: GRC Quantities and GRC Area Equivalent Per Zone

\begin{tabular}{ccc}
\hline Zone Number & Number of GRC units $(\mathbf{Q Z}, \mathbf{i}=\mathbf{1}: \mathbf{8})$ & Total GRC per zone $(\mathbf{m} 2)$ \\
\hline Zones $1,3,5$ & 350 & 4550 \\
Zones $2,4,6$ & 700 & 9100 \\
Zones 7,8 & 175 & 2275 \\
\hline
\end{tabular}

After interviewing the project construction managers and foremen, a preliminary schedule regarding this project's GRC installation was obtained as shown in Figure 3 below.
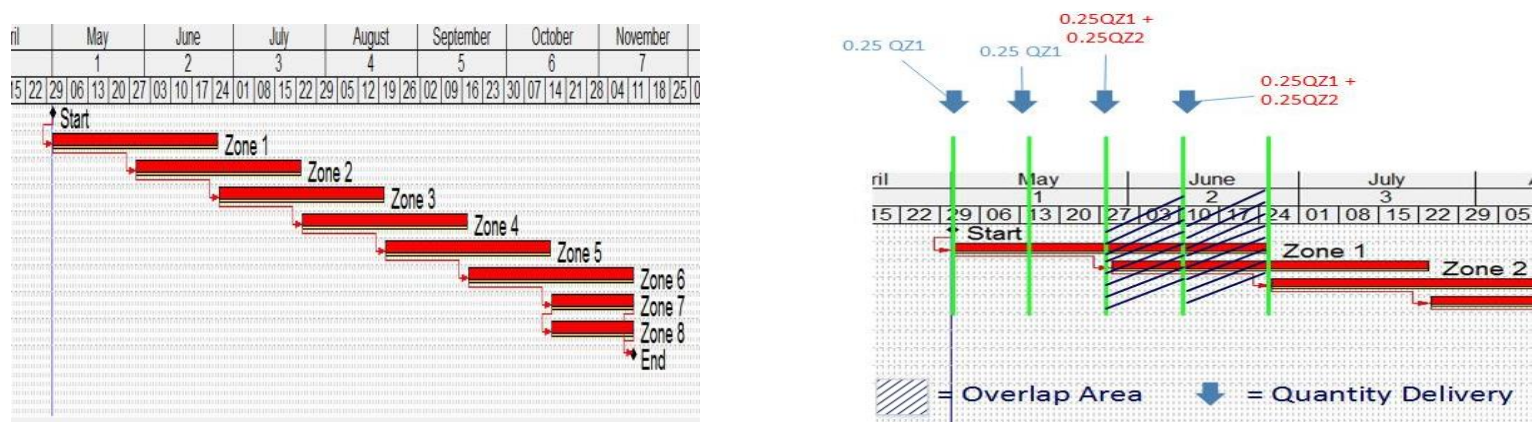

Figure 3: Preliminary GRC Installation Schedule (left) and Current Delivery Schedule (right)

Zones one till six have an eight-week installation period, whereas the smaller zones, seven and eight, have a four-week installation period. The overlap between the consecutive zones is shown in the schedule and is due to the fact that the irregular shape of the façade does not allow the complete installation of one zone unless the adjacent zone has started.

\section{BASE MODEL}

The base case model consists of the project's current site conditions. Information regarding the current site layout and procurement methods were obtained from the interviews. Currently, the available laydown space on site is $800 \mathrm{~m}^{2}$ distributed among the GRC racks, an electric generator, an equipment room, and one tower crane. Taking into consideration the area occupied by the motor, equipment room, and tower crane, the remaining space available for GRC units on site is constricted to $600 \mathrm{~m}^{2}$ equivalent to a total area of $1300 \mathrm{~m}^{2}$ in terms of GRC units (100 units). All material delivery orders arrive to the site on biweekly basis based on a push system. This is illustrated in Figure 3; green vertical lines equivalent to one-fourth of the quantity that needs to be delivered with regards to the zone under installation. For example, zone one has four scheduled deliveries, represented by blue arrow heads. At week zero and week two of the façade schedule, $0.25^{*} \mathrm{QZ}_{1}$ will arrive on site since installation is only concerned with zone one. However, at the onset of week four, GRC installation of zone two will commence, and therefore must have its $0.25^{*} \mathrm{QZ}_{2}$ 
delivered to it. There will then be an overlap between zones one and two in terms of deliveries, thus delivering on week four a total quantity of $0.25^{*} \mathrm{QZ}_{1}+0.25^{*} \mathrm{QZ}_{2}$. The same logic applies at the onset of week six. However, it should be noted that each delivery will require the use of four trucks. Each truck can deliver 22 GRC units to the site due to its limited capacity, therefore, these four trucks will move to the site carrying a total of $0.25^{*} \mathrm{QZ}_{1}$. When modelling the current push system on EZStrobe, it is important to define the model assumptions, activities, parameters, and outputs.

The main assumptions concerning the model under study are:

- A GRC unit surface area was assumed uniform with an average of $13 \mathrm{~m}^{2}$.

- The labor productivity was taken to be almost constant with slight variability which was portrayed in the distribution of the time duration of each activity.

- The trucks' capacity was assumed to be on average $286 \mathrm{~m}^{2}$ of GRC units (22 units).

- The area around the site could accommodate for a queue of four trucks.

- The total process duration of erecting GRC is 56 weeks. This duration was then divided into seven periods with each period equivalent to eight weeks and then modelled.

- The cost of the entire process was assumed to be the sum of the individual period cost.

Table 2 describes the main activities in the model and their duration distribution. The durations of each activity were recorded for a period of one month then fitted to the best statistical distribution.

Table 2: Model Activities

\begin{tabular}{|c|c|c|}
\hline Activity & Description & Time (minutes) \\
\hline MovetoSite & Transporting GRC from manufacturer to site & Normal $[20,4]$ \\
\hline EnterSite & $\begin{array}{c}\text { Trucks arriving to site and entering it only if there's an } \\
\text { available maneuvering space }\end{array}$ & 0.5 \\
\hline Unload & Unloading GRC units from trucks on site & Normal $[25,2]$ \\
\hline PrepareGRC & $\begin{array}{c}\text { Cleaning GRC units to ensure that they could be safely } \\
\text { hoisted to a crane }\end{array}$ & Normal $[70,1]$ \\
\hline InstallGRC & Installing GRC units on the roof & Normal $[50,1]$ \\
\hline
\end{tabular}

The unit cost of the model parameters are as follows: Truck cost is $30 \$ / \mathrm{hr}$, the cost of a helper is $20 \$ / \mathrm{hr}$, that of a skilled labor is $25 \$ / \mathrm{hr}$, the crane operator's cost is $35 \$ / \mathrm{hr}$, and the crane cost is $40 \$ / \mathrm{hr}$. The deterioration cost of a GRC unit is assumed to be $1 \$ / \mathrm{hr}$, and a $10 \$ / \mathrm{hr}$ fee is considered for truck delays. These inputs were based on the conducted interviews and were integrated into EZStrobe to deliver cost expenditures after the simulations performed ended.

The model outputs obtained after running the simulation which covers a two-month period of the project are described as follows: Total Cost (\$) is the summation of the total costs of the trucks used, labor, crane, in addition to the GRC units' deterioration cost, and 
truck delay cost. Resources Cost $(\$)$ is obtained by adding the cost of the used resources: trucks, labors, and cranes. The Deterioration Cost $(\$)$ is the cost of the total time a GRC unit spends on site before its final installation. The Turnover Rate (hours/occurrence) of the space is the time needed for the storage space on site to be replenished by a new GRC rack. Finally, the Truck Delay Cost $(\$)$ is the cost incurred by trucks waiting to be unloaded instead of performing another delivery.

The flow of GRC units in the current static site layout following a push system was modelled on EZStrobe as shown in Figure 4. The process starts by receiving the units on site, storing them in allocated areas, preparing them for installation, and finally installing them.

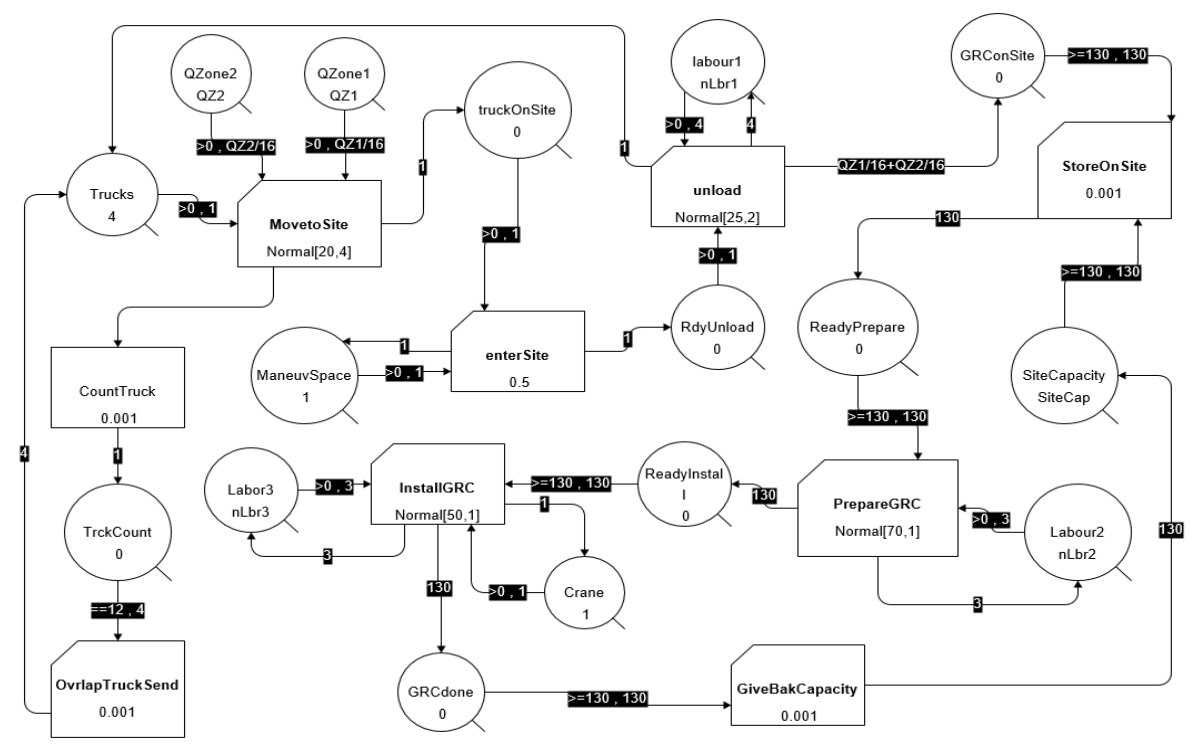

Figure 4: Current Model

\section{IMPROVED MODEL}

In the improved model, three improvement cases were considered:

Case A: This case adopts a pull system by reducing the lead time of GRC units from two weeks to one week. This is done by having two trucks deliver units to the site every week instead of four trucks every two weeks.

Case B: This case adopts a new improved model, as shown in Figure 5, to quantify the cost effect of merging two activities, the "Cleaning of GRC" and "GRC Installation" into one activity "PrepGRC". Combining the two activities would require less time than proceeding with each of the two mentioned activities separately. This is done by permitting the crane to transport one GRC rack, equivalent to ten GRC units, rather than one individual GRC piece at a time; workers clean the units on the rack while other workers hoist the rack itself to the crane. This reduces the number of times the activity of hoisting material (whether GRC units or racks) is executed. This is expected to improve resource utilization and to decrease the overall process time. 
Case AB: This case combined the changes made in cases A and B, and was implemented to test their combined effect.

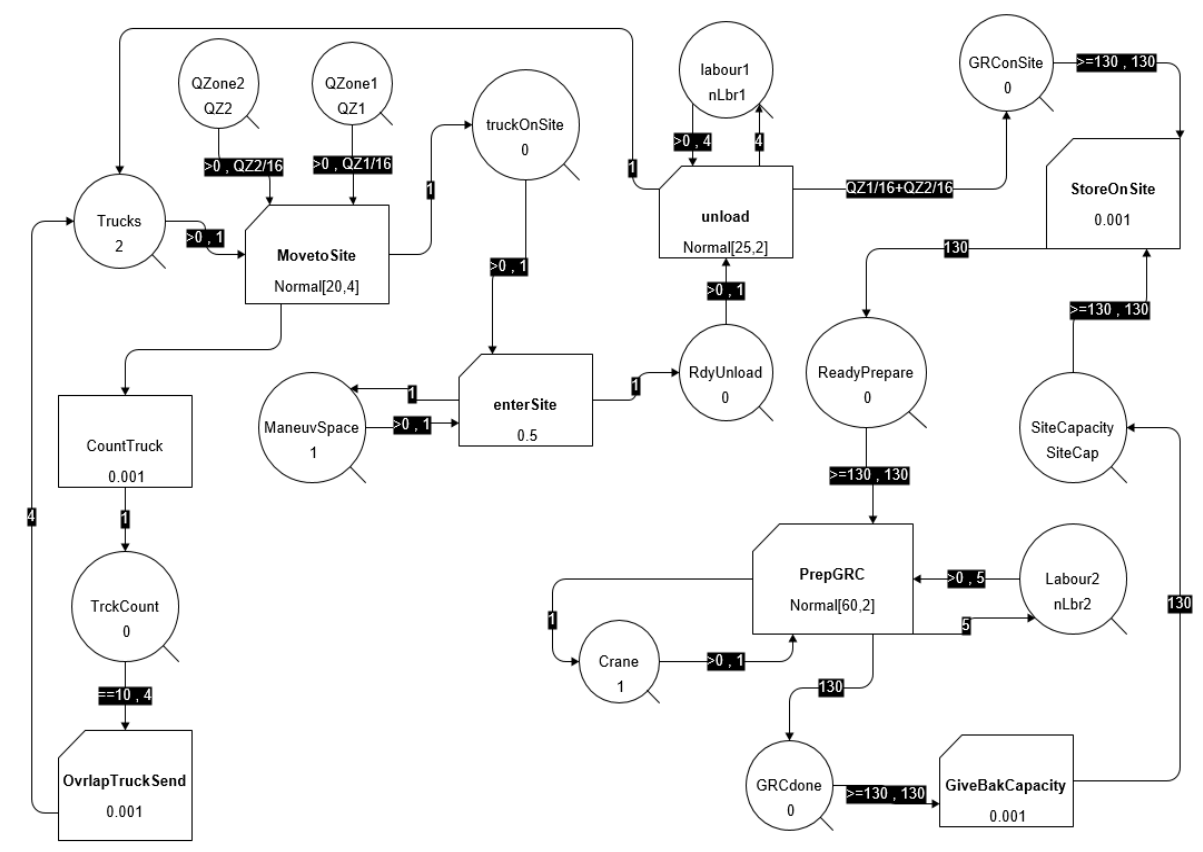

Figure 5: Final Optimized Model

\section{SIMULATION RESULTS AND ANALYSIS}

Results obtained upon simulating the three mentioned scenarios on EZStrobe in terms of total project costs, transport delay cost, material deterioration cost, material turnover in terms of inventory space, and total simulation time are shown in Table 3.

Table 3: Optimization Statistics

\begin{tabular}{|c|c|c|c|c|c|c|c|}
\hline & \multicolumn{4}{|c|}{ Cases } & \multicolumn{3}{|c|}{$\begin{array}{c}\text { Percent } \\
\text { Improvement }\end{array}$} \\
\hline & Original & $A$ & $\mathrm{~B}$ & $A B$ & $A$ & $B$ & $A B$ \\
\hline Total Cost $(\$)$ & $\$ 420,253$ & $\$ 414,576$ & $\$ 358,552$ & $\$ 353,925$ & 1 & 15 & 16 \\
\hline Truck Delay Cost $(\$)$ & $\$ 148$ & $\$ 66$ & $\$ 149$ & $\$ 66$ & 56 & 0 & 56 \\
\hline $\begin{array}{c}\text { Deterioration Cost } \\
\text { (\$/unit) }\end{array}$ & $\$ 37$ & $\$ 37$ & $\$ 31$ & $\$ 31$ & 0 & 16 & 16 \\
\hline $\begin{array}{l}\text { GRC Turnover } \\
\text { (hr/occurrence) }\end{array}$ & 11.9 & 11.9 & 10.1 & 10.1 & 0 & 15 & 15 \\
\hline Total Hours (hr) & 83 & 83 & 71 & 71 & 0 & 15 & 15 \\
\hline
\end{tabular}

Decreasing the lead time by one week (case A) contributed to a $56 \%$ decrease in truck delay cost and a $1 \%$ decrease in total process cost. Changing the sequence of two activities 
in near locations and minimizing unnecessary material movement on site (case B) reduced the project cost and duration by $15 \%$ each, and decreased the GRC turnover rate by $15 \%$ and thus their deterioration cost by $16 \%$.

Furthermore, the improved model (case $\mathrm{AB}$ ) did not only reduce the waste generated by unnecessary movement of GRC material between activities but also, it added value by maintaining the quality of the material through reducing time spend on-site which is shown in the increased turnover rate of GRC (15\% improvement). This can be quantified in the reduced deterioration cost from $37 \$ / G R C$ to $31 \$ / G R C(16 \%)$. The improved system (case $\mathrm{AB})$ performed well in terms of the total cost savings (16\%) and time savings $(15 \%)$. Decreasing the lead time showed a decrease in transportation delay cost $(56 \%)$ which is expected since a smaller number of trucks arrive at the same time and location and there is a higher spread time between truck arrival.

So, for the purpose of optimizing the costs associated with the supply and handling of GRC units, cases $\mathrm{B}$ and $\mathrm{AB}$ yielded the best results in terms of cost and time savings and are both recommended for diminishing the proposed process costs.

\section{MODEL LIMITATIONS}

One of the limitations of the suggested model is that the results proposed are associated with the first eight weeks of the schedule which corresponds to the erection of the first two zones on the project while the rest of the cost is assumed to be the sum of the seven eightweek period costs accumulated together. Another limitation is the fact that the model does not present the supply chain of GRC in its big picture; it only observes the material from the point of delivery on site to the point of installation on site. Therefore, the proposed optimization is limited to sub-optimizing part of the supply chain related to the endcustomer which is the construction site in this case.

\section{CONCLUSIONS AND RECOMMENDATIONS}

Space availability is a constraint in congested sites, so adopting a dynamic site layout is an efficient means to effectively allocate resources on site. A case study was conducted on a congested site in its finishing phase where GRC units were being delivered for installation on site. The simulation base model was developed based on the current state of the process. Then, three scenarios were discussed. The first scenario illustrates the benefits of adopting a pull system, the second involves combining and re-engineering activities with the purpose of decreasing material related expenses, and the third combines the latter with the former. Both the second and the third scenarios generated the most prominent results having a percent improvement of cost from the base model by $15 \%$ and $16 \%$, respectively in addition to $15 \%$ time saving. Thus, incorporating lean tools and allowing smooth flow of materials to the site within the simulation model proved to be beneficial for a congested site that adopts a dynamic site layout strategy.

Assumptions and limitations of the model were addressed and minimized as possible. Future work aims at improving the existing model to better reflect the actual site conditions regarding labor productivity and truck capacity of the site and developing it even further to include more activities to account for the interaction between different tasks on site. 


\section{REFERENCES}

Alves, T. d. C. L., Tommelein, I. D., and Ballard, G. (2006). "Simulation as a Tool for Production System Design in Construction." Proc. of the 14th Ann. Conf. of the Int'l. Group for Lean Construction. Santiago, Chile, 341-353.

Bascoul, A.M. \& Tommelein, I.D. (2017). "Visualizing Daily On-site Space Use." Proc. of the 25th Ann. Conf. of the International Group for Lean Construction. Heraklion, Greece, 597-604.

Bertelsen, S., \& Koskela, L. (2002). "Managing the three aspects of production in construction." Proc. of the 10th Ann. Conf. of the Int'l Group for Lean Construction. Gramado, Brazil.

Hamzeh, F.R., Tommelein, I.D., Ballard, G., and Kaminsky, P. (2007). "Logistics Centers to Support Project-Based Production in the Construction Industry", Proceedings of the 15th Annual Conference of the International Group for Lean Construction, IGLC 15, 18-20 July, East Lansing, Michigan, USA, pp. 181-191.

Koskela, L. (2000). "An Exploration Towards a Production Theory and its Application to Construction.” PhD Dissertation, Helsinki University of Technology.

Kraemer K., Henrich G., Koskela L. and Kagioglou M. (2007) "How Construction Flows Have Been Understood In Lean Construction." 4th International SCRI Symposium, as part of the 4th International Research Week (IRW proceedings). Rotherdam, 121-132.

Lange, S., \& Schilling, D. (2015). "Reasons for an Optimized Construction Logistics." Proc. of the 23rd Ann. Conf. of the Int'l Group for Lean Construction. Perth, Australia, 733-742.

Martinez, J. C. (1996). "State and Resource Based Simulation of Construction Processes." $\mathrm{PhD}$ Dissertation, University of Michigan.

Mossman, A. (2007). "Lean Logistics: Helping to Create Value by Bringing People, Information, Plant and Equipment and Materials Together at the Workface." Proc. of the 15th Ann. Conf. of the Int'l Group for Lean Construction. Michigan, USA, 198211.

Patel, K. V., \& Vyas, C. M. (2011). "Construction materials management on project sites." National Conference on Recent Trends in Engineering \& Technology. India, 1-5.

Said, H., \& El-Rayes, K. (2013). "Performance of Global Optimization Models for Dynamic Site Layout Planning of Construction Projects." J. of Automation in Constr., 36, 71-78.

Standridge, C. R., \& Marvel, J. H. (2006). "Why lean needs simulation." Proc. Of the 38th Conf. on Winter simulation. California, USA, 1907-1913.

Tiwari, S., Pawar, G., Luttmann, E., Trujillo, R. \& Sreekumar, A. (2018). "Visual Planning for Supply Chain Management of Prefabricated Components in Construction." Proc. of the 26th Ann. Conf. of the Int'l Group for Lean Construction. Chennai, India, 11501159.

Tommelein, I. D., and Zouein, P. P. (1993). "Interactive dynamic layout planning.' J. Constr. Eng. Manage., 119 (2), 266-287.

Tommelein, I. D. (1994). "Materials Handling and Site Layout Control." Proc. of the 11th Int. Symposium on Automation and Robotics in Construction, 297-304. 
Tommelein, I. D. (1997). "Discrete-Event Simulation of Lean Construction Processes." Proc. f the 5th Ann. Conf. of the Int'l Group for Lean Construction, 121-136.

Turanoglu, B., \& Akkaya, G. U., (2017). "The Dynamic Facility Layout Problems with Closeness Rate: A Fuzzy Decision Support System Approach.” Selçuk Üniversitesi Mühendislik, Bilim ve Teknoloji Dergisi

Uriarte, A. G., Moris, M. U., Ng, A. H., \& Oscarsson, J. (2015). "Lean, Simulation and Optimization: a Win-Win Combination.” 2015 Winter Simulation Conference, IEEE, Huntington Beach, California, USA, 2227-2238. 
Dargham AS., Assaf S., Faour K., Hamzeh, F 